\title{
Ecologically oriented humanitarian education managementin the context of the Russian federation subject's boarder territories sustainable development
}

\author{
$Y$. V. Dmitrieva*, and G.A. Galkovskiy \\ Pskov State University, Lenin Square, 2, 180000 Pskov, Russia
}

\begin{abstract}
This article presents the results of an interdisciplinary study aimed at identifying the effectiveness of introducing productive educational technologies into the system of ecologically oriented higher education in the Humanities. The system of higher humanitarian education is viewed in the context of sustainable development of the Russian Federation border territories (on the example of the Pskov Region). The author's solution for the development of higher humanitarian education in the context of sustainable development of the border territories of the North-Western Federal District is presented.
\end{abstract}

\section{Introduction}

The ecological component is an integral part in managing the systems allowing the maintenance of life and the development of the human mind. Environmental consciousness is a form of social consciousness at the stage of formation and development, which includes a set of ideas, theories, practices and motivations that mirror the process of interaction between a person and the surrounding world - the environment. The relevance of the stated topic is determined by the need to address the problem of the quality of environmental awareness formation in the system of higher humanitarian education.

The insufficient level of environmental education in Russia, the lack of an ecologically oriented approach in the fostering of the student's consciousness, and the ever-growing trend of consumer-like attitude to nature can be viewed as obstacles to the realization of harmonious connections between the environmental phenomena and man as a subject of cognition. In this regard, there is a need to form a new farsighted model of humanitarian education, which will be able to function as one of the key elements in the sustainable development system of a certain territory.

The focus of the modern scientific and pedagogical consciousness on the principles of the so-called "green economy" as a new conceptual paradigm of sustainable development of territories on a global and regional scales indicates the need to introduce the most effective and economically-efficient technologies of environmental education and design in the agenda of the economic entities of the Russian Federation.

\footnotetext{
${ }^{*}$ Corresponding author: uliadm@yandex.ru
} 
The socially-oriented focus and universality of the environmental education process population-wise, in which all levels of government, local self-government bodies and the media must participate, is defined in article 74 of Federal Law No. 7 "On Environment Protection" of the Russian Federation issued on 10.01.2002 [5]. At the same time, the socio-economic environment and environmental security act as crucial life-supporting component in the system of spatial development of the territory in the conditions of the border area thereof.

The awareness of inseparability of the following triad: "environment and man ecological literacy and culture of interaction - public environmental awareness and priorities for sustainable development of territories" - all this attracts close attention to the development and implementation of productive educational technologies in the context of human resource potential development.

This article presents the results of an interdisciplinary study aimed at assessing the effectiveness of the introducing productive educational technologies in the system of ecologically oriented higher education in the humanities in the context of regional development among the people from 18 to 25 years old.

The higher humanitarian education system of the Pskov region as a border entity within the North-Western Federal district constitutes the object of the research in hand; the main experimental ground is the Russian Philology and Foreign Languages Department of Pskov State University.

\section{Materials and Methods}

Nowadays, a fair amount of experience in implementing the concept of environmental education is accumulating in Russia: the concept of general environmental education has been developed, theoretical and applied research is being conducted in the field of the subject matter, organizational forms and technologies of thegeneral secondary and secondary vocational education (A. N. Zakhlebny, E. B. Osey, Sh. F. Farakhutdinov and others); there is an overall trend towards the "greening"or, in a broader sense, "ecologization" of the Federal Educational Standards for various higher education majors and the development of productive technologies in the system of higher ecologically oriented humanitarian education.

In general, the issues of fostering the environmental and legal literacy and ecological ethics and aesthetics remain unresolved; so far, there is no structure that defines the relationship between the interdisciplinary areas in the general and professional ecologicaluniversity training, there is no unity of scientific opinions on the subject of understanding the essence of the terms "productivity" and "productive educational technologies".

As part of the research, the goal was to analyze the relationship between regionality and the level of formedness and awareness ofthe sustainable development values among students of the Humanities block of bachelor's degree programs.

The hypothesis postulates the correlationbetween the place of residence and education and the level of awareness of sustainable development values in the regional context of an unstable border area.

The theoretical and methodological basis of the research includes the following scientific works:

- in the field of educational psychology - L. S. Vygotsky, D. I. Latyshina, L. D. Stolyarenko, and others.;

- in the fields of pedagogy and the history of education - V. V. Anisimov, R. B. Vendrovskaya, V. M. Klarina, N. V. Kuzmina, N. D. Nikandrov, A. I. Piskunov, M. N. Skatkin, and others; 
- in the field of applying the main points of the productive approach to training in the field of humanitarian education (M. O. Voloshko, Yu. V. Eremin, A.V. Rubtsova, etc.).

The discussion of the problem:

In the history of Russian science and pedagogical practice, the term "environmental/ecological education" has not always been actively used. The terms "environmental awareness", "environmental safety" and "environment protection" have been frequently used in theacademic discourse for many decades. This fact is often overlooked by researchers of different areas of state education policy, mainly pointing out the straightforward thesis of not identifying the essence of these conceptual categories and the feasibility of their use in the context of ecologically oriented productive educational technologies.

It is customary to distinguish between productive education, productive learning, productive teaching and productive support of the students.

Traditionally, ecological education is considered to be a system of social norms, rules, knowledge, skills and abilities aimed at ensuring the long-term interests of a person in their environment. However, it is not taken into account that the meaning of the word "conscious" and "consciousness" has changed over the course of time. The original meaning of the Lat. "com" (with, thoroughly) and "scire" (to know) spurred the meaning of "be (mutually) aware of". This implied the bilateral influence of the subject and the object of cognition. The later Latin word "conscius" - "knowing, aware", shifted its meaning to the awareness of the subject of cognition leaving aside the thesis of the convergence between the two sides of the process: the subject and the object, which is excluded from the awareness phenomenon. In the later word "conscious" one finds another shade of meaning, that is "knowing, privy to" that implies a form of the knowledge, hidden from the person. In this case, the connotation of the subject-object interaction process is lost. When focusing on the development and implementation of productive educational technologies in the system of ecologically oriented humanitarian education, the latter is of particular importance.

Within the framework of the current research, the productivity of the educational process in the system of higher humanitarian pedagogical education is viewed as the realization of a person's potential, his powers (E. Fromm); the ability to productively use their powers and capabilities, as the potential of a developing personality and the unity of the material and ideal personal-significant product; human capital realized in selfdevelopment. It is also worth pointing out that productivity without self-development is impossible.

Traditionally, productive education in the main body of research papers is treated as a learner-centered education technology in the emerging network of educational routes, which is a sequence of academic and practical modules, independently selected by individuals and ensuring the increase of general education and culture level, professional guidance, the efficiency of undergoing various stages of professional education, the confident entry of the person into the society taking into account his aptitudes and personality traits.

In the narrow sense, "productive education" is the kind of education that has a result. In this sense, any educational system is productive, since it has a certain graduate with a certain document on education as its result. The productivity of the teacher's work is expressed in his or her classroom activity management.Each lesson is regarded as a product of the teacher's work.

Not all researchers agree with this interpretation of the productivity of education and the educational process. Trying to explain the productivity of traditional education, they usually refer to the social significance of the activity performed by the subject of the educational process. At the same time, it is frequently left unnoticed that the orientation should not only be on the standard, but on the personally-significant knowledge. 
Productivity in teaching is the implementation of the child's project-oriented initiative as a planned educational product. This takes into account the potential of each individual. Humanistic productive education is presented as a project production within the student's continuous activity, based on the assessment of his or her project initiatives and the feasibility thereof.These initiatives in a specific social environment or the educational situation become a tangible result of applying a set of knowledge and skills, constitutingthe learner's competencies.

Language consciousness/awareness and speech production act not only as the basic components of the psychophysiological, but also the spiritual and mental basis of the student's personality in the process of applying technologies of ecologically oriented education in a regional context; the process of speech production can be considered as a process of exteriorization of internal conscious states of a person as a unique ecosystem in the macro system of general ecological functioning.

The productivity ofthe ecologically oriented educational process awareness depends on many factors, namely: the motivation of the student and teacher, achievement orientation, the need and ability to learn, the ability to perform, the amount of learning time and the regularity of training; activeness and perseverance in discovery and the observation skills, ability to stimulate and manage the learning process by the teacher.

The productivity of the educational process in the system of the ecologically oriented humanitarian education is manifested primarily in the mindfulness of teaching and learning, namely in the development of ecological thinking; the focus on "self" is the essential basis of the productive approach, that is, its conceptual basis.

The interpretation of the phrase "productive learning" assumes three meanings:

- the quality of the creative, productive, economic or social activity of a person, the result of which is a product - material, intellectual, spiritual.

- "productive thinking", "productivity of intelligence", which reflects the quality of the effectiveness and originality of the intellectual activity of the individual.

- the result of the educational system functioning that provides a social product in the form of the fate of people and communities living on a certain territory.

It should be noted that the baseline for the overall value of the term "productivity" is the concept of "development" that in 1963, the ad hoc group of experts on community development, working under the auspices of the UN, it was explained as a process in which the actions of the people themselves are united with the actions of the authorities to improve the economic, social and cultural conditions of communities, to integrate these communities into the general flow of life of the nation, to give them the opportunity to contribute to national development.

This understanding of productivity in human life, as well as in his or her education, focuses on understanding the essence of the term "sustainable development", which has an English origin and literally means "continuously supported or self-supporting, acceptable, balanced development". There is no consensus in the academic world regarding the interpretation of the term "sustainable development", which was first introduced into scientific and practical use by the International Commission on environment and development (the "Our future" report [8]) in order to denote social development that does not undermine the natural environment of human civilization. At the same time, sustainable development was understood as development that meets the needs of the present, but does not endanger the ability of the future generations to meet their needs (World Conference on the Environmental Issues, Stockholm, 1972) [7]. In 1992, the term "sustainable development" was used as a new concept for the existence of all mankind. At the same time, most interpretations emphasize the importance of the regional aspect in shaping the values of sustainable development. The theoretical origins and main interpretations of the 
term 'sustainable development' in the scientific literature and documents of a conceptual and strategic nature are presented in Table 1.

Table 1.Theoretical origins, main interpretations of the term "sustainable development" in scientific literature and documents of a conceptual and strategic nature

\begin{tabular}{|c|c|}
\hline \multicolumn{2}{|c|}{ Theoretical origins of the idea of "sustainable development» } \\
\hline Author & Interpretation of the term "sustainable development» \\
\hline O. Comte, P. Spencer, K. Marx & Classical theory of social development \\
\hline I. Kant, A. Schweitzer & Ethics and aesthetics \\
\hline V. V. Vernadsky & The doctrine of the biosphere and the noosphere stage of its development \\
\hline D. Bell & Theory of post-industrial society \\
\hline A. A. Gorelov & Ecological humanism \\
\hline \multicolumn{2}{|c|}{ Main scientific interpretations of the term "sustainable development" } \\
\hline $\begin{array}{l}\text { V. A. Koptyug, academician, } \\
\text { Chairman of SB RAS (end of } \\
\text { the XX century) }\end{array}$ & $\begin{array}{l}\text { - is a model of society development that meets the basic life needs of } \\
\text { both the current and all the generations to follow; }\end{array}$ \\
\hline M. A. Kuvshinov & $\begin{array}{l}\text { - is the deliberate process of socio-economic system of the municipality, } \\
\text { ensuring the stability of relations, elements and structure of the system as } \\
\text { a whole in the direction of growth of the level and quality of life within } \\
\text { balance with the environment. }\end{array}$ \\
\hline \multicolumn{2}{|c|}{$\begin{array}{c}\text { Main interpretations of the term "sustainable development" in the documents of a conceptual and strategic } \\
\text { nature }\end{array}$} \\
\hline Source/document & Interpretation of the term "sustainable development" \\
\hline $\begin{array}{l}\text { World conservation strategy } \\
\text { (1980) }\end{array}$ & $\begin{array}{l}\text { - is the development that provides a real improvement in the quality of } \\
\text { life of people and at the same time preserves the natural diversity of the } \\
\text { Earth; }\end{array}$ \\
\hline $\begin{array}{l}\text { The report of the Commission } \\
\text { Brundtland (1987) Russian } \\
\text { translation, } 1989\end{array}$ & $\begin{array}{l}\text { - is a development in which current generations meet their needs, without } \\
\text { depriving future generations of the opportunity to meet their own needs, } \\
\text { needs; }\end{array}$ \\
\hline $\begin{array}{l}\text { The world Bank (the end of XX } \\
\text { century) }\end{array}$ & $\begin{array}{l}\text { - is the management of the total capital of society in the interests of } \\
\text { preserving and multiplying human capabilities }\end{array}$ \\
\hline
\end{tabular}

In the report "Our common future", sustainability refers specifically to the ordering of technical, scientific, environmental, economic and social resources, namely the importance of how and in what way the regional system can be maintained in a state of equilibrium in time and space. The balance is maintained by value orientations that determine the sustainable development of the territory within the framework of the integration model "science - business - power", where education is the leading basic factor of potential development.

Therefore, within the concept of sustainable development of the system of ecologically oriented education in the Humanities "regionalism" is understood both as "an administrative and territorial unit in the system of government, and as a form of existence of historically formed social environments and how social environment that shapes the material-existential conditions of life, and as informational and motivational sociallyoriented space with a special community-focused information field".

However, not all researchers take into account that sustainable development is dynamic and is not an unchanging state of harmony, but rather "a process of change in which the scale of resource exploitation, the direction of investment, the vector of technical development and institutional changes are consistent with the current and future needs", without destroying the stability of the value orientations of the individual and the society (M. A. Kuvshinov) [4]. Special attention is paid to the problem of forming the values of sustainable development for groups of the population aged $12-17$ and $18-25$.

Education for sustainable development is an education that makes possible the social transformations necessary to create a new socially just society, which should not be limited 
only to the inclusion of disciplines in the school system that aim at fostering the values of sustainable development and appropriate environmental behavior.

There is an academic opinion that a value characterizes a person, manifests itself as his or her attitude to the world and other people. Thus, I. I. Dokuchaev, defining value as an existential center, states that cultural values, combined and embodied in the totalities of human forms of life and life stories, penetrate into the world of his communicative practice, where existence is expressed and a certain equality of subjects performing certain communicative actions is ensured, provided that distancing is excluded [3].

Such scientific views make it possible to more reasonably regard ecological humanism as the methodological basis of ecologically oriented humanitarian education, which is conceptually aimed at the implementation of the following value and outlookideas:

1) a holistic idea that implies recognition of the unity of the world of nature and the world of man, the "inclusiveness" of man and his natural activities in the socio-natural environment, its assessment;

2) the universal value and self-worth of nature, which is designed to overcome the utilitarian and solely practical attitude;

3) harmonization, optimization, humanization as the main directions of rational and effective nature management;

4) preserving the experience and traditions of ecologically sustainable nature management, aesthetics and harmony of cultural landscapes [2].

In this regard, the opinion of A. A. Gorelov that the basic axiological basis of the XXI century culture, including the culture of education, is environmental humanism, formed by co-evolutionary values, is quite convincing.

In the course of the research, the specifics of modeling professional mobility of a teacher were studied with a focus on the basic points presented in the works of $\mathrm{V}$. N. Vvedensky, N. D. Kachugurov, M. I. Lukyanova, A.V. Khutorskoy and other scientists. The problem of optimizing communicative language training in the course of the study was considered with a focus on the scientific work of N. A. Rybakova, D. I. Ivanova, K. R. Mitrofanov, O. V. Sokolaeva and other specialists.

Basicresearchmethods:

1. method of complex theoretical analysis of pedagogical, philosophical, methodological and psychological-pedagogical literature within the framework of the subject of the claimed research;

2. the method of organized observation, questioning, testing, theoretical modeling and expert evaluation, namely: the method of free associations; The "Alternative" method.

Investigation stages:

1. Determining the importance of environmentally-oriented humanitarian education in the system of sustainable regional development (on the example of the Pskov region);

2. Determining the subjective level of significance of ecologically oriented humanitarian education in the system of sustainable regional development (from the position of a student of Pskov state University in the direction of training 44.03.05 "Pedagogical Education").

3. Study the features of the value-motivational sphere of the subjective level (on the example of studying the value-motivational sphere in the process of implementing productive educational technologies in the process of training students of Pskov State University in the direction of training 44.03.05 "Pedagogical Education"). 


\section{Results and Discussion}

Results of an interdisciplinary study to identify the effectiveness of the introduction of productive educational technologies in the system of ecologically oriented higher education in the context of sustainable development of the border territories of the subject of the Russian Federation (on the example of the Pskov region):

1. Scientific and theoretical aspects of ecologically oriented higher humanitarian education in the context of sustainable development of border territories

Sustainable development is much more than teaching basic knowledge and principles related to the sustainable development of the territory in schools, it is not actually ecology, environmental education and enlightenment. It is necessary to distinguish between the education about sustainable development, in which students gain knowledge directly about the concept of sustainable development and its principles, and education for the sustainable development, when students develop skills to anticipate the consequences of their actions, critical and systematic thinking, the ability to build and develop partnerships, as well as the ability to fully participate in discussions, discussions, negotiations, take all possible responsibility and make decisions, which is directly related to the concept of productive technology, used in the educational process.

The formation of consciousness and self-awareness is inextricably linked with the development of the content of human culture, with the mastery of historically established social norms of behavior, thinking, and language rules. Its structure becomes more complex, and the forming cognitive processes are differentiated and improved, forming a complex structure. The objective world is reflected in an increasingly generalized and abstracted form, more fully and deeply. Ensuring a coordinated interaction between formal education, public awareness of various issues, and the training of certain skills in order to create a more stable future is the main goal of sustainable development. Education for sustainable development is the kind of education that enables social transformation and the achievement of sustainable development.

Taking into account that the environmental factor is a basic component of all human life maintaining systems, it is more reasonable to use the terminology "ecologically oriented" humanitarian education. The management of this type of education in the regional aspect is understood not so much as the regulation of educational processes in the administrativeterritorial system, but as providing conditions for the development of the internal potential of a person living in a given territory, taking into account the specifics of geopolitical features and historical and cultural landmarks. Health, as a basic human right and the main goal of civilization development, determines the quality of the environment, as well as the quality and standard of human life, first of all. Therefore, it is impossible to fully develop a genuine human attitude to nature and man as a special biological system in the system of systems of the surrounding world without ecologically oriented humanitarian education.

Therefore, it is reasonable to distinguish the following basic aspects in the content of the ecologically oriented humanitarian education: scientific (ensures the development of a cognitive attitude to the environment), value-based (forms a moral and aesthetic attitude to the natural environment, overcomes excessive rationalism and consumerism), normative (focuses on mastering the system of norms and rules, regulations and restrictions of an environmental nature, intransigence to any manifestations of violence) and activity-based (includes types and methods of human activity, aimed at the formation of cognitive, practical and creative skills of an environmental nature, the development of strong-willed qualities of students, the need and ability to be active in resolving environmental issues).

The productivity assessment of the technologies for ecologically oriented humanitarian education in the border territories of the Russian Federation cannot be carried out without taking into account the peculiarities of the geopolitical space, as well as the behavior and 
constructive interaction of the population with the environment in the conditions of inhabiting a "borderline" territory. This implies the introduction of such a criterion as "environmental risk", which is the subjective probability of adverse consequences in the interaction of humans and the environment. The importance of the environmental risk awareness is an important link between ecologically oriented humanities education and the behavior of teachers and students on the territory of residence.

The authors of the article accept the concept of "sustainable development of human settlements" in the modern scientific interpretation, presented in the documents of the Istanbul conference on urban development in 1996: stimulating local economic development (expanding the economic potential of the territory, regulating demographic processes, creating jobs, business infrastructure, improving the competitiveness of enterprises, etc.); land use based on the assessment of social and environmental impact; preventing further degradation of the environment and personal development, overcoming the unhealthy living conditions. This is important to take into account when implementing technologies for ecologically oriented higher education in the context of regional development for the population aged 18-25.

Consequently, the most important aspect of fostering the values of sustainable human development is regional self-identification as one of the components of a civil identity.

We believe that regionalism is in close interdependence with the level and the peculiarities of social and market territory development, processes of modernization, stagnation or regression, and cannot influence the formation and change of values of sustainable development among the population, and most of all, at the age of $12-13$ and $17-18$; age 25 is estimated as a period of formation of the basic values of sustainable development.

In accordance with these factors, the life strategy of a young person should include thepreferable attitudes that are resonant with the development strategy of the region.:

- $\quad$ work in the production sector in this particular region;

- getting a professional education;

- willingness to improve professional skills in order to develop themselves and improve the well-being of both their own family and members of the community in the region;

- creating a family, giving birth, raising children;

- positive self-identification in relation to the historical and cultural heritage of the territory of residence, the desire to make their own contribution to the development of this heritage.

2. Scientific and analytical aspects and criteria for evaluating ecologically oriented higher humanitarian education in the context of sustainable development of border territories

Quantitative indicators for assessing the implementation of productive technologies in the field of ecologically oriented higher education in the context of sustainable development of border areas: basic demographic and socio-economic indicators in dynamics over the study period, as well as indicators of sustainable development of higher education in the humanities.

The qualitative value of an educational product is the ratio of the total number of students who have mastered the exercises on the formation of an educational product, evaluated as " 4 " and " 5 " to the total number of students in the framework of a productive educational model.

3.The results of an interdisciplinary study to assess the effectiveness of the introduction of productive educational technologies in the system of ecologically oriented higher education in the context of regional development of the population aged 18-25 in the Pskov region. 
Due to the historical objective factors of the development of the Russian state, the state border and the border borders of the North-West do not represent a zone of sustainable cross-border development. Pskov region is a region that has historically developed in a "mobile" or "unstable" border area, which, it would seem, does not allow us to declare territorial priorities in the formation of value orientations for sustainable development. However, the results of an interdisciplinary study to identify the effectiveness of the introduction of productive educational technologies in the system of ecologically oriented higher education in the context of sustainable development of the regional space (the Pskov Region) in the period $2015-2019$ have shown:

The demographic situation and well-being of the population living on the territory of the subjects of the Russian Federation, usually does not depend on their border position (border subjects occupy both the leading positions among other subjects of the Russian Federation, and the lowest positions). Despite the unique geopolitical location and the total area of the territory of 55.3 thousand $\mathrm{km} 2$ in the integral rating of border subjects of the Russian Federation for the studied period, the Pskov region occupies the lowest positions in terms of population size and quality of life (65-75). The population of the Pskov region is 19.5 times smaller than that of the leading region (Moscow) and 14.5 times higher than that of the outsider regions (the Nenets Autonomous district); there is a pronounced decline in the population, including as a result of outbound migration to larger cities in search of more well-paid work. The low level of wages in the labor market of the Pskov region forces young people to focus on leaving for other regions (priority places of departure: the cities of St. Petersburg, Moscow, Veliky Novgorod, Smolensk). From 2015 to 2019 - these are mainly certified specialists in the pedagogical profile, and, most of all, teaching the Humanities block of disciplines (the largest percentage of departures $81 \%$ are the graduates in the 44.03.05 "Pedagogical education" direction of training). At the same time, the number of scientific and analytical publications (observations and questionnaires analysis) that demonstrate positive results in the formation of sustainable development values in the regional aspect on the territory of the Pskov region is steadily increasing. These studies cannot always be described as reliable.

Evaluation of target indicators for the analyzed period for the effectiveness of the implementation of the Subprogram "Sustainable rural development for $2014-2017$ and for the period up to 2020 " represents implementation by 52, $2 \%-60 \%$ (final average score). At the same time, $0 \%$ of achievements are shown by the indicators "level of gasification of apartments" (rural areas) and "provision of rural population with drinking water"; only $60 \%$ of the indicator "Improvement of housing conditions of citizens living in rural areas, including young families and young professional".

In the rating of regions by the number of students, the Pskov Region ranks 23-27; there are 7 universities in the region, state - 43\%; non-state-57\%; implementing humanitarian training programs-3, pedagogical - 1 .

The total number of students enrolled in bachelor's, specialty, and master's programs during the study period (2015 - 2019) is an average of 16 thousand people, of which 7,427 are at Pskov state University, which is $46 \%$ of the total number in the region. The total number of teaching staff (without external part-timers) is 491 people; the share of students who are not provided with a hostel from among the needy is 0 . Pskov state University ranks 171 out of 436 in the overall ranking of higher education institutions; the number of programs of study in the Humanities is 6. [6]

The difficulty of admission to the Pskov state University in the General ranking 3 out of 5 points; the attractiveness of the learning process is 4,5 of 5 points; teacher professionalism is 4,5 out of 5 points; the level of quality of education in the region is 4,7 out of 5 points; the level of research work is 4.8 out of 5 points. 
The average use score of students accepted for full - time education is 65, 15; the indicator for the 44.03.05 "Pedagogical Education" direction of training is slightly higher than the average and is 6.9 .

The research results show that:

- the most developed action-influative component (4.78 points), which is explained by the direct participation of most students in outdoor work (homesteads, living in rural areas);

- students have an average level of dominance of subjective attitude to nature, which is explained by the low significance of wildlife in the life of each of the students (from 4.1 to 4.99 points).

From all of the above mentioned, we can draw the conclusion that the values of sustainable development are the most significant in the lives of Pskov State University students. This conclusion can be explained by the "good" level of ecologically orientedhumanitarian education, as well as by the activity of students, who are not indifferent to the problems of the environment in the world as a whole, and in their region in particular. This is due to the fairly effective work of the authorities, including the field of education and the main areas of environmental policy. Pskov region is a region with the ecological potential.

Pskov State University has approved a plan of events dedicated to the Year of Ecology in Russia. The total number of environmental activities is 32, of which 12 reflect the specifics of regional development, which is a very high percentage $(37.5 \%)$.

At the same time, it is necessary to note the negative trends of ecologically oriented humanities education, namely, a rather low level of introduction of productive technologies, which is confirmed by the following data from the survey of students: out of the total number of respondents, only 1 has chosen the phrase "language is a tool for learning" as an answer to the question about the functional orientation of language disciplines; while almost $60 \%$ of the total number of survey participants expressed interest in using productive technologies in the educational process and insufficient use of this type of technology in teaching practice.

\section{Conclusions}

It is worth mentioning that young people have mixed feelings both towards their place of residence and towards Russia in general. At the same time, people living in the urban settlement of Porkhov are driven by love for their "small homeland", but pride and the feeling of respect for their place of residence are not shown positively enough. Attention is also drawn to the percentage of the small-town respondents who do not have any positive emotions, but are primarily concerned with money. This is due to the high level of unemployment in the region and the low standard of living of the population. Depressive development of the territory cannot but be the cause of the general state of depression among the population, including young people.

We should also note the decline in the demographic indicators of this territory, especially for the age group of the population from 12 to 18 . Special measures initiated by the authorities of the Russian Federation at the local level were only slightly able to have a positive impact on the dynamics of the birth rate, which in this time period is associated with the age groups from 0 to 7.

According to the survey, young people in the image of "homeland" are driven by personal emotional characteristics and associations with the "small homeland", place of residence, family, customs, traditions, home, which, unfortunately, does not always have a positive evaluation. This statement also applies to the issue of ecological essence. Only a few aimat actively improving the ecological situation in the life of "the place where I live", although almost all would like to live in an environmentally friendly area. 
In General, there is a General trend in the Pskov Region towards introducingthe productive educational technologies in the system of ecologically oriented higher humanitarian education in the context of regional development for the population aged 18 25.

Therefore the hypothesis of the research has been partially confirmed.

\section{Recommendations}

In order to improve the quality of ecologically oriented education and upbringing in the educational institutions located on the territories of the so-called "small towns", it is recommended:

- to the authorities carrying out the activities for the organization and conducting annual monitoring of the environmental education and upbringing quality;

-to Pskov State University the development and implementation of productive educational technologies;

In order to increase the level of understanding of the content of sustainable development values by teachers and students and to understand their significance in the managing of practical work, it is recommended to familiarize all the participants with the results of the study in hand.

\section{References}

1. Z. Abdullaev, Philosophical Sciences, 2,186(1991)

2. A. A. Gorelov, Ecology: textbook (1998)

3. I. I. Dokuchaev, Value and existence. Fundamentals of the historical axiology of culture. SPb.: Nauka(2009)

4. M. A. Kuvshinov, the Concept of management.., (2011)

5. Federal Law No. 7 "On Environment Protection" of the Russian Federation issued on 10.01.2002, http://www.consultant.ru

6. Ranking of all Russian universities, https://vuzoteka.ru/

7. United Nations Conference on the Environment, 5-16 June 1972, Stockholm, https://www.un.org/

8. Report of the World Commission on Environment andDevelopment: Our Common Future, https://sustainabledevelopment.un.org/ 